\title{
Psychological variables of CrossFit participants: a systematic review
}

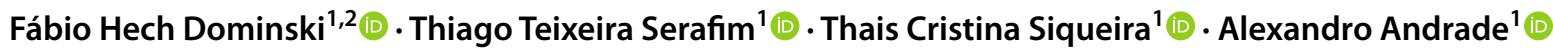

Received: 26 March 2020 / Accepted: 30 July 2020 / Published online: 29 August 2020

(c) Springer-Verlag Italia S.r.l., part of Springer Nature 2020

\begin{abstract}
Objective This study aimed to review the existing literature concerning the psychological variables of CrossFit participants. Methodology This review followed the PRISMA guidelines and was documented in the PROSPERO registry (CRD42018091177). Six electronic databases (SCOPUS, PubMed, SPORTDiscus, Web of Science, EMBASE, and Cochrane) were searched from their inception through July 2020. The methodological quality of the studies was assessed.

Results Thirty-four studies met the inclusion criteria. We observed an increase in satisfaction, clinical addiction, and enjoyment among participants related to exercise, social improvement, and high intrinsic motivation to participate for the purpose of enjoyment, challenge, and affiliation. Perceptions of effort were high among CrossFit participants. Some studies found that the reaction time was impaired after the CrossFit session, whereas others found no changes in mental health, self-esteem, and well-being after training.

Conclusion Adherence and maintenance of the practice of CrossFit are related to psychological variables such as motivation and satisfaction of basic psychological needs. CrossFit participants demonstrated high perception of effort, intrinsic motivation, and reasons for practice such as enjoyment, challenge, and affiliation. The quality assessment demonstrated the need for more detail in the methods section of future investigations. Additional high-quality studies are needed to investigate the effects of CrossFit training on the mental health of participants.
\end{abstract}

Keywords Sport psychology $\cdot$ High-intensity interval training $\cdot$ Motivation $\cdot$ Mental health $\cdot$ Mood

Electronic supplementary material The online version of this article (https://doi.org/10.1007/s11332-020-00685-9) contains supplementary material, which is available to authorized users.

Fábio Hech Dominski

fabio.dominski@udesc.br

Thiago Teixeira Serafim

thiagotserafim@outlook.com

Thais Cristina Siqueira

thais.siqueira@udesc.br

Alexandro Andrade

alexandro.andrade.phd@gmail.com

1 Laboratory of Sport and Exercise Psychology (Lape) of the Santa Catarina State University (Udesc), Pascoal Simone, 358, Coqueiros, Florianópolis, SC 88080-350, Brazil

2 Univille University, Joinville, SC, Brazil

\section{Introduction}

Extreme conditioning programs (ECPs) are physical exercise programs characterised by high intensity and high volume, with short or no rest periods $[1,2]$. ECPs through exercise from gymnastics, weightlifting, calisthenics and others, aim to foster the development of physical fitness in several domains such as cardiorespiratory fitness, strength, flexibility, and power [3].

Among ECPs, some training methods have emerged as registered trademarks, such as Insanity ${ }^{\circledR}$, Gym Jones ${ }^{\circledR}$, $\mathrm{P} 90 \mathrm{X}^{\circledR}$, and $\mathrm{CrossFit}^{\circledR}$, the latter of which has shown greater popularity and growth [2]. CrossFit is characterised by a relatively new method of physical training that includes the performance of functional exercises of constant variation, from running and rowing to Olympic Weightlifting (e.g. Snatch and Clean and Jerk), and gymnastic movements, as well as plyometric and calisthenics, which are performed at a high intensity [4]. CrossFit aims to develop components of physical fitness related to health and motor performance: aerobic capacity, muscular strength and endurance, stamina, 
flexibility, speed, coordination, accuracy, agility, balance, and power [3].

CrossFit has been gaining popularity since its inception and implementation about 20 years ago, with significant growth in the number of participants and in the number of gyms offering the practice, called 'boxes' [5]. CrossFit boxes are located in 142 countries across all 7 continents, currently totalling more than 14,000 affiliates [6]. Evidence shows that high-intensity modalities have shown significant growth amongst different populations including healthy individuals, obese individuals, and athletes [7-9].

There has been a trend in recent studies to carry out research on psychological factors in sports [10] with respect to the effects of physical exercise on health [11] and the influence of psychological aspects on athletes' performance [12]. However, review studies on CrossFit [2, 13] have mainly focused on the effects of CrossFit on components of physical fitness focusing on the five domains of physical fitness (cardiovascular/respiratory resistance, endurance, strength, flexibility and power) and on possible injuries in CrossFit participants $[14,15]$. In addition to improving the physical conditioning of practitioners, the recent expansion of CrossFit may be associated with psychological variables of participants, such as motivation, which leads people to adhere to and maintain exercise [16]. In this sense, we highlight the study of motivation in the field of Sports and Exercise Psychology [17]. As reported by Dominski et al. [16], CrossFit training is conducted with a great sense of belief and identify, with inherent rewards influencing exercise adherence. However, there is a need to know about other psychological variables that can influence in the participation such as mood states [18]; anxiety [19]; body satisfaction [20]; psychological needs and behavioural regulation [9].

Gathering information on the motivation and psychological needs of participants can contribute to the understanding of growth and interest in CrossFit, their influence on adherence to and maintenance of physical exercise practice [21], and psychological aspects related to recreational performance, athlete performance [22], and injury [15].

The CrossFit training shows peculiar characteristics including the sense of community promoted by the training group mode with a supportive and tight-knit community [23], the functionality and scalability of movements and exercises [24], the motivational and the competition environment including self-challenge not only through breaking of personal fitness records, but also among the pairs [25, 26]. Furthermore, it is recognized that the CrossFit environment emphasizes the body's function over its appearance [27], differing from traditional resistance training modalities. CrossFit encourages individuals to change their behavior, influencing the adoption of a healthy lifestyle, involving general practitioners of varying levels of fitness and athletes as a sport modality [28].
A comprehensive review of the available literature, considering multiple psychological variables related to health and performance can foster the understanding of this type of training, collaborating for evidence-based practice, and to highlight gaps in the literature and offering directions for future research. In view of the current levels of physical activity around the world, knowledge about the influence of psychological variables on individuals' participation in CrossFit may be useful to promote exercise interventions that boost long-term adherence. In sum, the aim of the present study is to review the existing literature concerning the psychological variables of CrossFit participants, with a view of distinguishing between short-term (acute) and long-term (chronic) effects.

\section{Methods}

\section{Registration and guidelines}

This systematic review was conducted according to the recommendations from the Preferred Reporting Items for Systematic Reviews and Meta-Analyses (PRISMA) [29]. The review was recorded in the International Prospective Register of Systematic Review (PROSPERO) registry (registration number CRD42018091177), prior to completion of formal screening of search results based on eligibility criteria. The PRISMA checklist is provided in the Supplementary material.

\section{Search strategy}

Studies were searched using the following electronic databases: SCOPUS (Elsevier), PubMed (National Library of Medicine and National Institutes of Health), SPORTDiscus via EBSCO, Web of Science (Main collection-Thomson Reuters Scientific), EMBASE, and Cochrane Library. The search strategies for each database are provided in the Supplementary material. The search terms used in the databases were "extreme conditioning program*" OR "crossfit" OR "high-intensity functional training" OR "crosstraining" AND "psychology" OR "sport psychology" OR "exercise psychology" in the search fields of the databases. This strategy was permuted in all databases, with integrated searches in the title, abstract, and subject fields. We searched these databases from their inception through July 2020.

The Web of Science database was prioritised in decisions regarding duplicate articles, and such searches were carried out in the Core Collection in the basic research field with the terms for the topic item and the time stipulated as all years. The supplementary material contains the search strategies used in each database. 


\section{Manual search and grey literature}

References lists of all identified studies were searched for further relevant articles [30]. Eight additional studies were identified from the manual search. Besides that, the search strategy was complemented with a comprehensive search of the 'grey' literature, including publications not published in indexed peer-reviewed journals.

\section{Eligibility criteria}

We included only original articles that investigated psychological variables of CrossFit participants. A CrossFit participant was defined as a person who practices CrossFit as an athlete or common participant at least three times a week. We included studies that investigated the following topics related to the psychology of CrossFit participants for the analysis: attention, activation, cohesion, cooperation, cognition, concentration, coping, feedback, flow-feeling, leadership, motivation, satisfaction, self-determination, sense of community, decision making, mental health, perfectionism, personality, mental training, and visualisation (related to participation), abandonment, addiction, aggression, anxiety, burnout, dependence, dropout, mood, body image, perception of competence, self-confidence, self-efficacy, self-esteem, depression, emotions, stress, reaction time (related to psychological effects of participating).

Only quantitative and qualitative studies (or mixed method) with an abstract and full text available online until July 2020 and in the English, Spanish or Portuguese languages were included. We did not restrict the search by starting date. We excluded review articles, case studies, conference papers, editorials, and letters.

Eligibility criteria for this systematic review were based on the Population, Intervention, Comparator, Outcome, Study design (PICOS) statement [31] (Table 1).

\section{Study selection and data extraction}

Two reviewers (FHD and TTS) independently performed the search and assessed the eligibility of each article. Discrepancies were solved by a third researcher (TCS). We screened all included titles and abstracts and reviewed the full text of articles that met our predetermined inclusion and exclusion criteria. The authors (FHD and TTS) independently extracted the data from all included studies.

Our search identified 646 articles; the full text of 34 was reviewed, and 26 were selected, besides 8 further studies identified by reference checking, totalling 34 studies included in the narrative review. A PRISMA flowchart of the search is presented in Fig. 1. Full references of included studies are provided in the Supplementary material.

After study selection and data extraction, analyses were carried out regarding the study design: cross-sectional, experimental, and qualitative. We extracted the following data: title, authors, journal, year of publication, objective of the studies, sample (number of subjects, gender, age, and level), study design, type of intervention, and main study results. Because our objective focused on a broad range of psychological factors, we have divided the discussion section according the prevalence of psychological variables studied. If findings related to a variable appeared in at least two studies, then this was considered to be a specific topic in the discussion, and the variables in a topic were grouped.

\section{Quality assessment}

Quality assessment of the 34 studies that met the inclusion criteria was performed using three established scales (STROBE, SRQR, and TESTEX) according to the study design (cross-sectional, qualitative, and experimental, respectively). Two independent reviewers (FHD and TTS) evaluated each of the 34 studies using the three established scales, and the assessment of each study is described in supplementary material (Tables S6, S7, and S8).

To assess the methodological quality of the studies, the recommendations of STROBE (Strengthening the

Table 1 Eligibility criteria for inclusion of studies in a systematic review

\begin{tabular}{|c|c|c|c|}
\hline & & Inclusion & Exclusion \\
\hline $\mathrm{P}$ & Participate & Any CrossFit participant & Participants of other types of physical exercise \\
\hline I & Intervention & CrossFit & $\begin{array}{l}\text { Massages, manual therapy, stretching, alternative therapies, weight } \\
\text { training, walking or running, high-intensity interval training } \\
\text { (HIIT) }\end{array}$ \\
\hline $\mathrm{C}$ & Comparision & $\begin{array}{l}\text { With healthy individuals or not, with groups of other } \\
\text { physical exercises or control group without interven- } \\
\text { tion }\end{array}$ & - \\
\hline $\mathrm{O}$ & Outcome & Psychological aspects & - \\
\hline $\mathrm{S}$ & Study & Cross-sectional, randomized and non-randomized & Case studies, review, meta-analysis \\
\hline
\end{tabular}




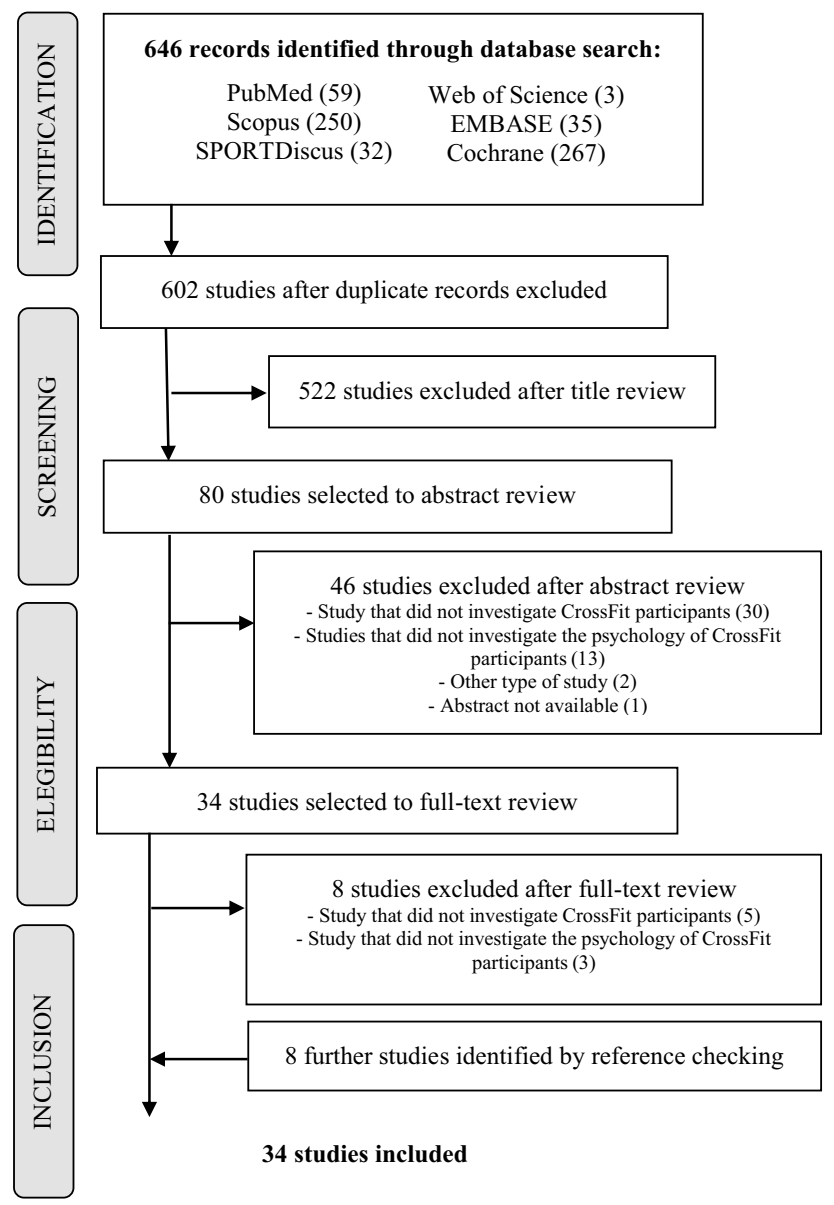

Fig. 1 Flow diagram illustrating literature research and selection process

Reporting of Observational Studies in Epidemiology) were followed, by means of the STROBE statement Checklist of Items That Should Be Included in Reports of Cross-sectional Studies [32]. This checklist includes 22 items that received a score from 0 (does not meet) to 1 (meets), where total adherence is expressed as a percentage of the items present.

The Standards for Reporting Qualitative Research (SRQR) recommendations [33] were used to evaluate the qualitative studies. This scale has 21 items, and each study was given a score from 0 to 21 and was coded as being of low (score of $0-7$ ), medium (score of 8-14), or high quality (score of 14-21).

The TESTEX (Tool for the assessment of Study quality and reporting in Exercise) [34] scale was used to evaluate the quality of experimental studies. This scale was designed specifically for use in exercise training studies, and it uses a 15 -point scale ( 5 points for study quality and 10 points for reporting).

\section{Results}

Exercise psychology themes such as motivation, adherence, self-esteem, attention, well-being, body awareness, exercise addiction, effort, mood, anxiety, social identity, athletic identity, sense of community, enjoyment, personality, perception of body competence, satisfaction with body image, and mental health were identified.

\section{Overview of the research}

In total, the 34 studies included 7101 participants, comprising 6122 (86.21\%) CrossFit participants and 979 (13.79\%) participants of other types of exercise, who composed the control group. The sample comprised 3749 (52.79\%) men and $3352(47.21 \%)$ women. Two studies analysed athletes $(n=94)$ of CrossFit $[19,35]$.

Four studies (11.77\%) used a qualitative (semi-structured interview and focus group) design, and the remaining 30 studies $(88.23 \%)$ used a quantitative design (cross-sectional $n=20$, experimental $n=10$ ). One study used a mixed method (quantitative and qualitative design), but the study was classified as quantitative due to the predominance of this design. Regarding cross-sectional studies, the adherence to the STROBE criteria varied between 36.3 and $83.3 \%$. The median TESTEX score for experimental studies was assessed as 6 (min. 1; max. 14).

Tables 2 and 3 present the sample characterisation and results found in the studies with a cross-sectional design (20 studies), experimental (10 studies), and qualitative design (4 studies), respectively.s

\section{Cross-sectional studies}

The results of cross-sectional studies revealed an increase in satisfaction [9, 36], addiction [3] from exercise, social enhancement [9] and sense of community [26], and high intrinsic motives for practice to gain enjoyment, challenge, and affiliation [7, 37, 38]. The studies showed that the perception of effort was high among CrossFit participants $[36,39,40]$ and that competence-related goals were higher among more experienced individuals [41]. Weekly training frequency was also related to greater social capital and a greater feeling of community [23], as well as with body image [42]. The length of participation was positively related to relatedness and enjoyment [43], and negatively associated with disordered eating [38]. There is no link between CrossFit participation and self-esteem [38, 49]. Studies have noted that men have more performance-related goals [41] and that they are more motivated by factors associated with challenge, social recognition, competition, strength, endurance, 


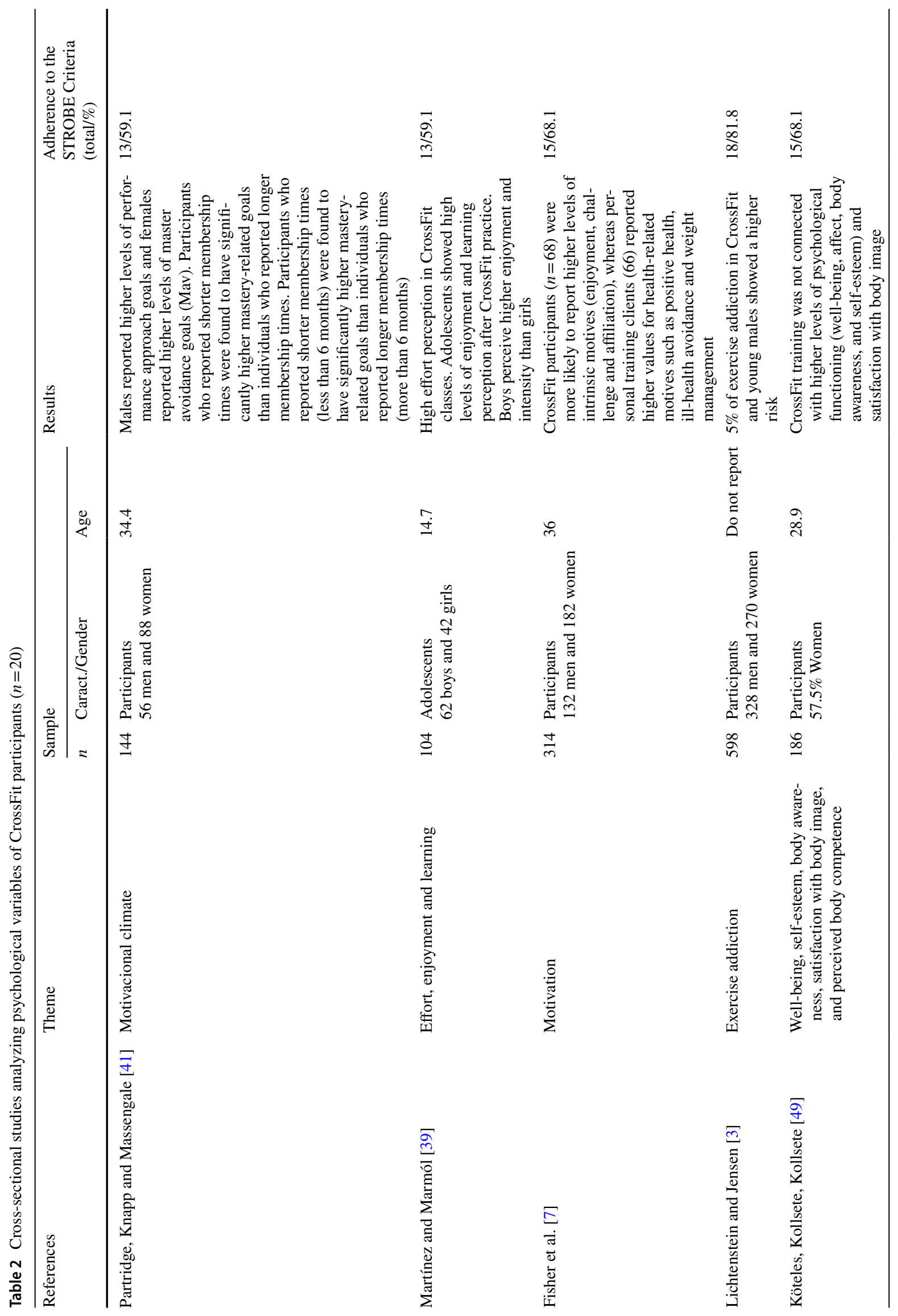









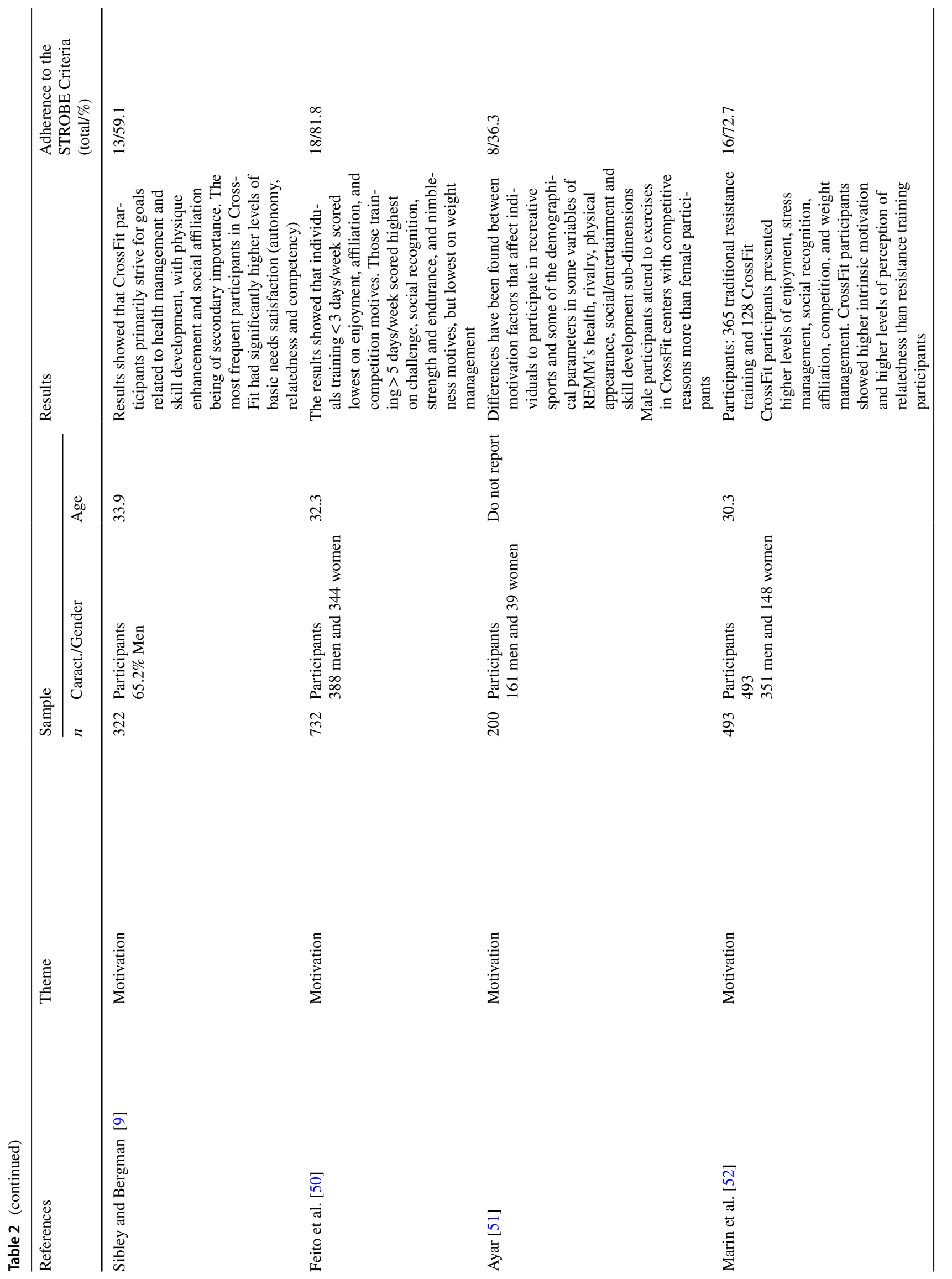




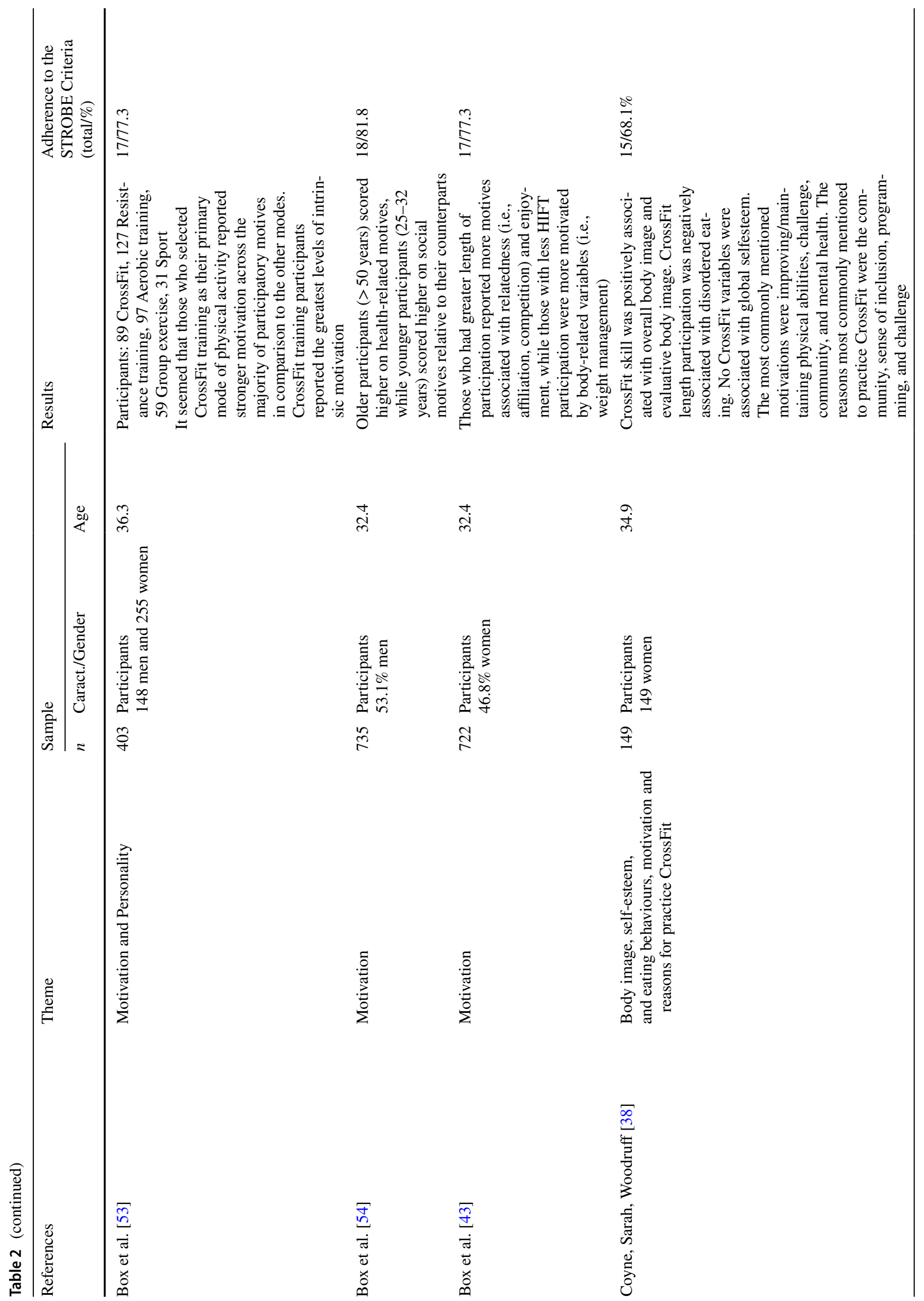


Sport Sciences for Health (2021) 17:21-41

29

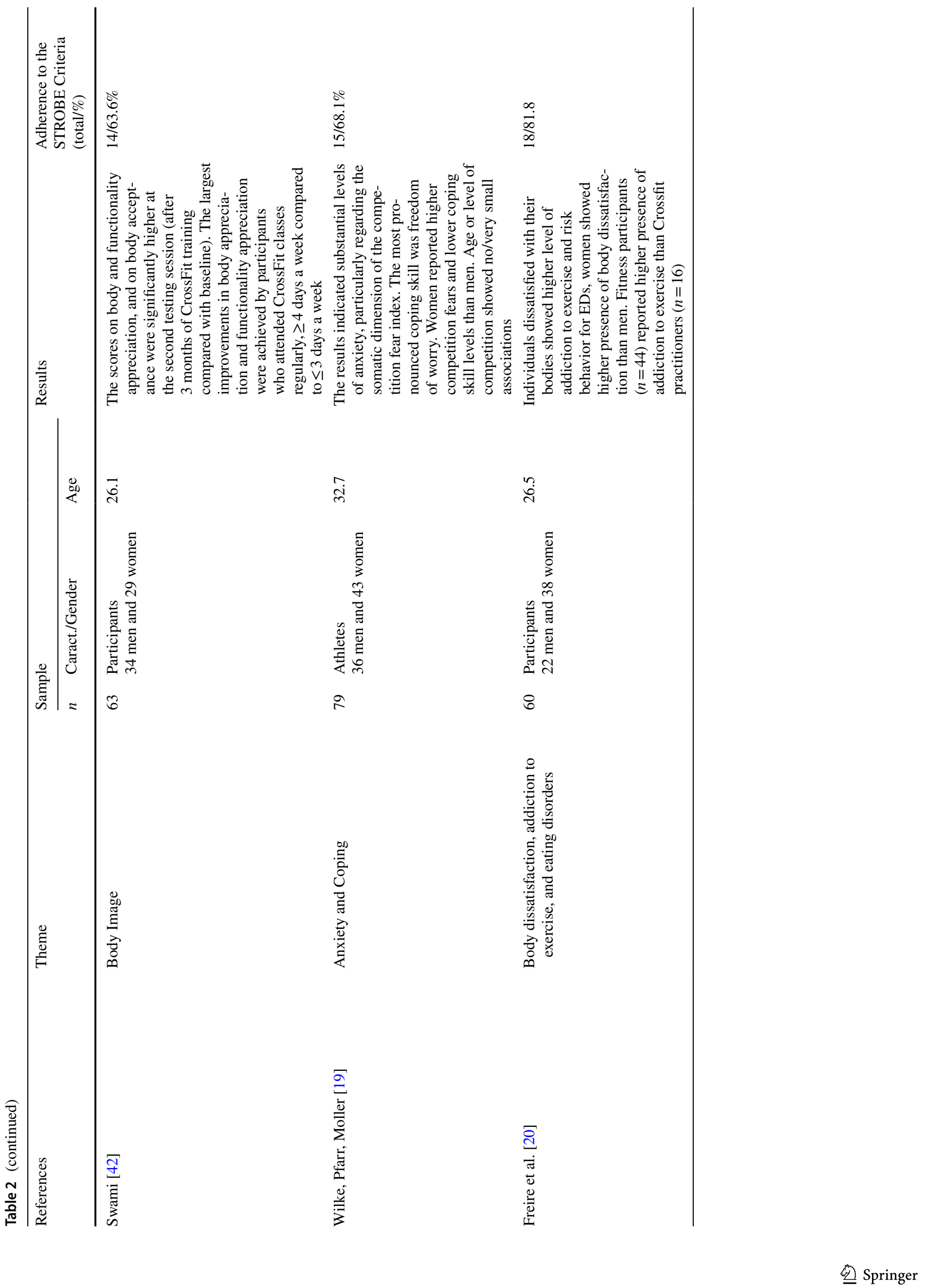




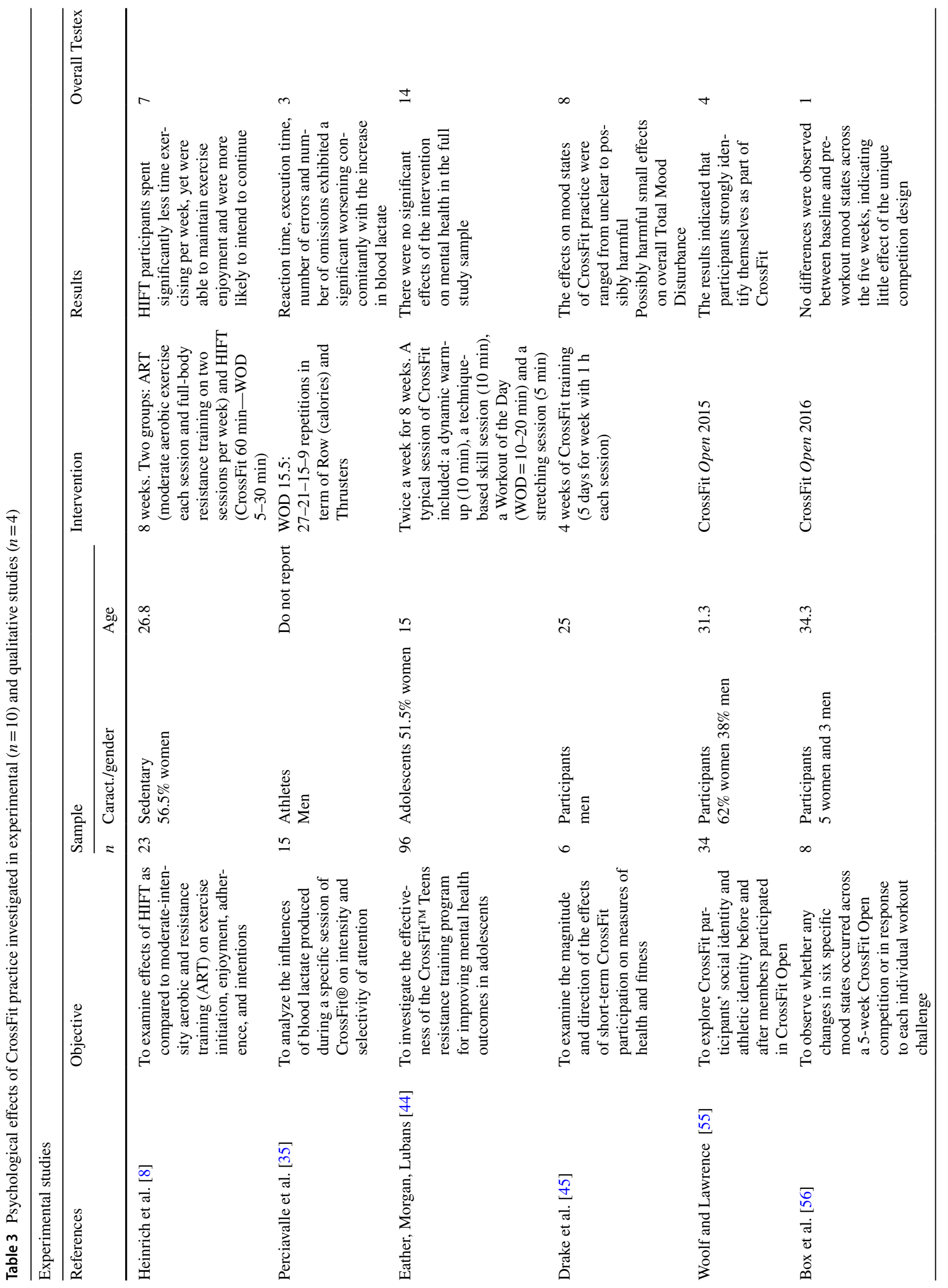









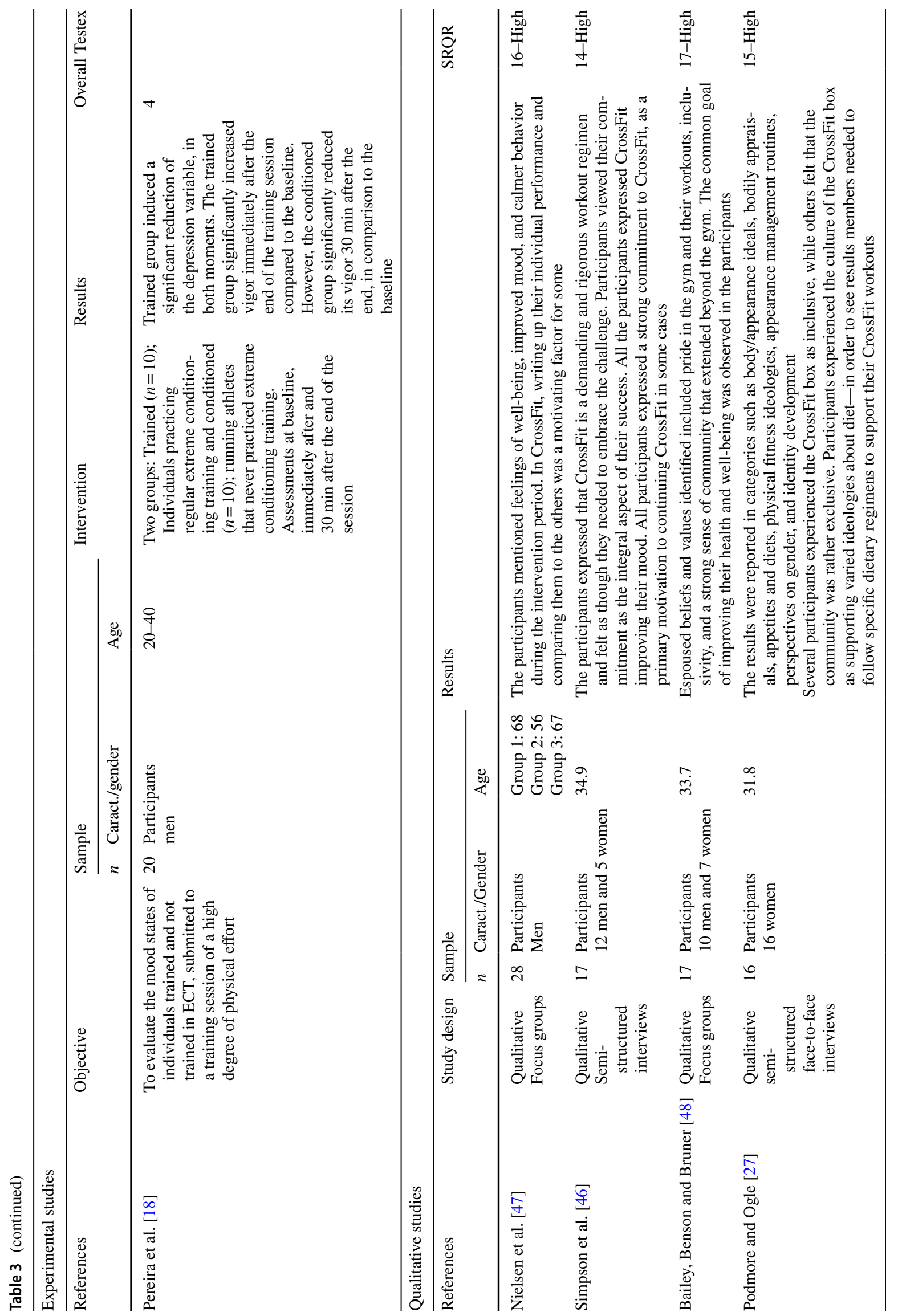


and agility [37] than women. Such goals relate to avoiding incompetence in tasks [41], and they are motivated by factors related to stress, weight control, and appearance [37].

\section{Experimental studies}

Experimental studies have found no changes in mental health [44] and well-being after CrossFit training. Concerning the consequences of CrossFit training, in an acute effect, some studies have found that reaction time was impaired, and that there are mood changes after a CrossFit session [18, 35]. Regarding chronic effects, a study showed that mood may be impaired [45]. The objective, sample characteristics, intervention, results, and score in quality assessment of the experimental studies are presented in Table 3.

\section{Qualitative studies}

Qualitative studies were conducted through semi-structured interviews and focus groups to investigate the factors that encourage individuals to adopt CrossFit as an exercise program [46], the motives that lead individuals to continue or discontinue a physical exercise program such as CrossFit [47], and the organisational culture of CrossFit [48]. In addition, the development of women's body image and appearance management practices was investigated [27]. Qualitative studies have demonstrated high methodological quality, as assessed by the SRQR. The theme, sample, and results of the studies are presented in Table 3.

Implications from the results of the investigated studies can be generated to collaborate the utility of CrossFit practice, mainly with respect to factors related to motivation, adherence, and maintenance regarding training (Table 4).

\section{Discussion}

This is the first systematic review that has synthesised comprehensively and deepening the current state of scientific production on the psychological variables of CrossFit participants. We analysed the motivation for participation and determined the effects of CrossFit on the psychological variables of participants. Knowledge production on the psychological variables of CrossFit participants is recent. Due to the greater number of studies investigating the themes motivation and mood, we analysed and discussed these variables separately, while psychological factors assessed relating to psychological health and performance were incorporated into the remaining sections of the discussion. Furthermore, the practical implications of the studies were described based on the results. The 34 selected studies were not suitable for quantitative synthesis through meta-analysis, owing to the lack of homogeneity regarding study design and data analysis. Consequently, we performed a qualitative synthesis to summarise and explain the characteristics and findings of the selected studies.

\section{Motivation for participation}

Based on the results of their study, Fisher et al. [7] suggested that the reasons (intrinsic reasons and reasons related to enjoyment, challenge, and affiliation) for participants to join CrossFit resemble those related to sports. Such factors may influence participants to keep the practice in the long-term in comparison with other modalities of resistance exercise [59]. However, attention should be paid to the inverse relationship observed in environments characterised by high-intensity activities in which engagement in this type of activity is likely to reduce pleasure [60]. Due to the lack of studies on dropouts of CrossFit [17], we point out the urgency of studies specifically on the motivational characteristics that lead the participants to dropout versus continue; this may improve the understanding of physical exercise behaviours related to high-intensity functional training modalities. According to meta-analysis of Reljic et al. [61] in high-intensity interval training (HIIT), the exercise intensity was not related to dropout, with lower dropout rates than commonly reported for traditional exercise programsmoderate-intensity continuous training.

Self-determination theory (SDT) has been proposed to account for motivation in physical activity and sports $[59,62]$ and it was the dominant theory in the studies we reviewed. Basic psychological needs theory (BPNT), a subtheory of SDT, suggests that we have three psychological needs: autonomy, competence, and relatedness. The satisfaction of these needs is related to the motivation of the individual to practice physical exercises [63]. Two studies have shown that CrossFit frequency is related to significantly higher levels of basic needs satisfaction with respect to all three needs [9, 36]. On the other hand, Köteles et al. [49] found that a high frequency of CrossFit training was not related to well-being, affection, body awareness, self-esteem, and body satisfaction.

In the case of CrossFit, relatedness is clearly fostered by the sense of community promoted by CrossFit, as this sense of belonging to group favours participation [23, 36, 45, 55]. In this regard, one of the characteristics of the modality is group training, so everyone can perform the exercises independently of their physical fitness level-scalability. For this, there are categories, called Scale (exercises performed with the least intensity of adapted form, usually destined to beginners) [55] and RX (exercises with a higher level of difficulty, usually destined to experienced participants). The social characteristics of CrossFit, which refer to affiliation and relatedness which arguably have contributed to its growth in popularity [7]. 


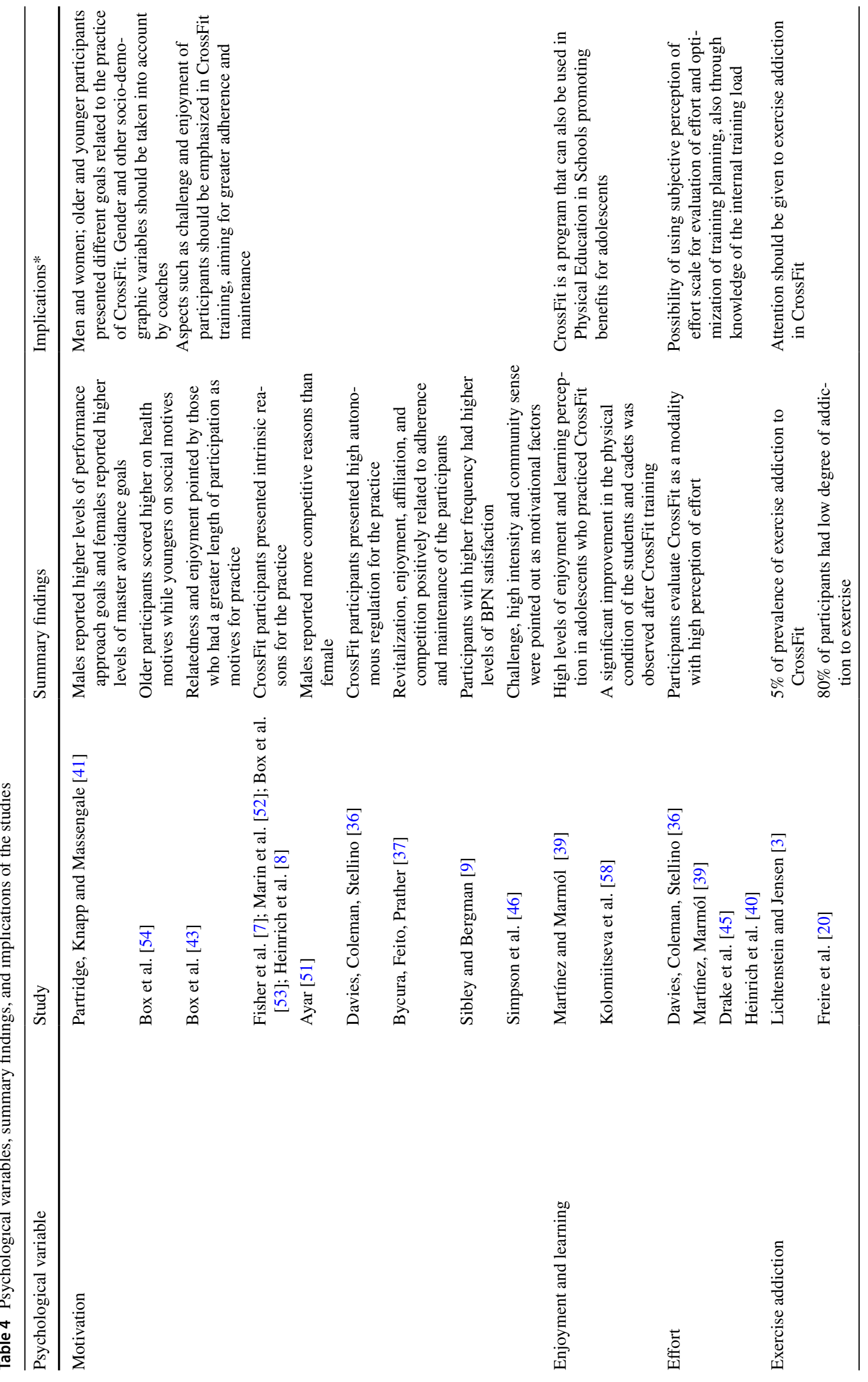







Competence was the strongest predictor of high levels of identified and intrinsic regulations in the study of Sibley and Bergman [9]. A common practice in CrossFit is to record performance in training and competitions (personal record), which is related to the load performed, as well as the number of repetitions and time. This characteristic fosters competitiveness and progress for each individual, increasing the participant's sense of competence [3, 47].

The goals promoted by the CrossFit boxes environment, related to accomplishing tasks and learning new skills $[38,45]$ shows that the extrinsic motivation appears in a more autonomous way in the context of CrossFit training. Davies, Coleman, and Stellino [36] noted that for professionals working in the field, it is clear that boosting autonomous aspects and increasing the motivation to practice will foster satisfaction among participants seeking basic psychological needs. In this sense, autonomy is related to the performance of the professional responsible for practice. According to Sibley and Bergman [9], when participants are offered the possibility of choosing exercises and the level of intensity, there is an increased sense of autonomy. Also, the monitoring of each individual's progress and continuous pursuit of performance optimisation may be aspects that promote autonomy [37].

Similar to sports environments, CrossFit training has assumed a social nature, with the creation of communities [26] in which the sense of affiliation is an important characteristic and an elementary condition for the support of the basic psychological needs [7]. We observed that more autonomous forms of motivation appeared in CrossFit training participants, so the motivational characteristics indicated an autonomous form of extrinsic motivation (identified as integrated regulations, and by intrinsic regulation). Therefore, people engaged in CrossFit training may achieve such goals as enhancing their own identities through exercise $[7,50]$.

Although CrossFit participants demonstrated intrinsic motivation, and reasons for practice such as enjoyment, challenge, and affiliation, this is preliminary evidence. Box et al. [43] found similar results in individuals who actively engage in HIFT, the participants with greater length of participation reported more motives associated with relatedness, as affiliation, compared those with less HIFT participation.

Thus, future investigations should examine the potential role of motivation on psychological health. Considering individuals that are more extrinsically motivated to perform CrossFit, for example, aiming for better physical appearance or improving physical abilities/skills [38], these participants may be more likely to suffer adverse effects on psychological health (e.g., developing body image disorders), when compared to individuals that are intrinsically motivated, according to previous research autonomous motivation has been shown to reinforce positive mental health outcomes [64]. 


\section{Mood}

The effect of physical activity and sport participation on mood state has been extensively researched. Numerous studies have investigated both change in mood states arising from exercise and the relationship between mood and performance [12]. However, there has yet to be a great interest among researchers in CrossFit-five studies addressed the theme, possibly because it is a fairly recent ECP.

Experimental studies showed that the results regarding effects of CrossFit on mood ranged from unclear to possibly harmful, with some of the mood factors showing likely detrimental effects and without differences between baseline and pre-workout, across weeks in the CrossFit Open Competition $[45,56]$. The negative mood changes after CrossFit arose from the stimulus generated by both the high volume and intensity of the modality $[45,56]$. Similar findings were found in studies with basketball and soccer athletes [65, 66]. On the other hand, two qualitative studies have shown improved mood among participants after CrossFit training [46]. Sławińska, Stolarski, and Jankowski [57] found that CrossFit training performed in the morning boosted mood and that participation in intense physical exercise may compensate for the negative effects on moods of non-optimal time-of-day exercise.

Considering the inconsistencies, and the initial stage of research that the theme is in, this variable lacks new investigations on CrossFit, as variations in mood are associated with sports performance. Some studies have shown that there may be negative changes to mood as a consequence of the intensity of training, participation in competition, or periodization of training [67]. Regarding acute effects, Pereira et al. [18] found that after one session of training, there were significant changes, albeit small and moderate, in mood states in trained and untrained individuals. It was observed a significant increase in vigour immediately after and reduction in fatigue $30 \mathrm{~min}$ after the end of the session. In this sense, research should be conducted on the effects of CrossFit practice on mood—both acutely and chronically.

\section{Psychological health}

It is clear from the review findings that more studies are needed on the relationship between CrossFit and psychological health. Considering the impact of the COVID-19 pandemic on people's lives, exercise should be promoted as a form of psychological self-care [68, 69], including CrossFit. Few studies were found that investigated mental health and well-being and the differences after CrossFit training $[27,44]$. In addition, neither study found effects of CrossFit training on self-esteem [38, 44, 49]. The body image was improved with the CrossFit training, mainly related to the development of skills, since this modality focuses on body's function over its appearance [38, 42].

The significant growth of ECPs such as CrossFit has been driven by the interest of the population as healthy individuals, obese individuals, and athletes. Then, due to more people involved and exposed, there is more chance to some participants have problems arising from excessive practice. In this context, we highlight the study of Lichtenstein and Jensen [3] that reported a prevalence of exercise addiction of 5\% related to CrossFit, measured by the Exercise Addiction Inventory. Behavioural indicators were found between addiction and the tendency to exercise despite injuries and feelings of guilt when one is not able to exercise. Attention should be paid to the satisfaction with body image in CrossFit participants, because this variable is recognized as a mediator factor for the development of addiction to exercise [20].

\section{Performance}

CrossFit is a high-intensity functional training (HIFT) [70] with short or no time for rest. Such practice implies large variations in effort levels and significantly interferes with the subjective perception of effort [36, 39, 40].

The perception of effort in relation to CrossFit sessions was considered high by participants in some studies [36, 39, 40]. This is closely linked to exercise intensity [71], considered a defining characteristic of ECPs. Compared with moderate-intensity training, CrossFit participants spend less time exercising each week and are more likely to continue exercising. Considering that lack of time is one of the most common reasons given for the physical inactivity [72], the high intensity and consequent reduced time spent in the activity are advantages presented by ECPs such as CrossFit, being well placed to address physical inactivity in the general population, considering this perceived barrier.

As practical implications, the researchers of sport and exercise science could use an instrument to evaluate the subjective perception of effort in the practice of CrossFit, as the monitoring of the perception of effort can allow better control of training load, in order to minimize the risk of injuries [73] and excessive training (overtraining and burnout). We can obtain the internal training load of each individual using the rating of perceived exertion (intensity) multiplying by the total duration of the training session [74]. Such assessment becomes essential in the case of ECPs such as CrossFit, where training intensity is often high.

Regarding performance, the intensity and selectivity of athlete's attention decreased after CrossFit sessions [35]. Concomitant to the increase in blood lactate was an increase in reaction time, number of errors in task execution, and number of omissions. 
With the exception of one study, all cross-sectional studies selected for review met $50 \%$ or more of the criteria defined by STROBE. Most of the items that did not meet the criteria were related to the methods section-mainly bias and sample size, reporting any efforts to address potential sources of bias and explain how the study size was arrived at, respectively. Of these, only five studies presented high quality, with compliance of items above $80 \%$. These results suggest the need for future investigations to provide additional details in the methods section. On the other hand, such details in methods were observed in the qualitative studies, mainly in relation to the methods for processing and analysing the data, with high methodological quality. In the review by Claudino et al. [13], of the 32 articles selected, only two studies presented a high level of evidence with a low risk of bias. There is thus a need for better quality in some aspects of the experimental studies involving the practice of CrossFit, especially with respect to the specification of randomisation and allocation concealment-characteristics that were absent in most of the studies reviewed.

\section{Practical implications}

Several practical implications can be generated from the results of the studies. To increase the adherence and maintenance of the CrossFit practice, we pointed out that emphasis should be placed on some characteristics present in the practice of the modality, such as the challenge that the exercises themselves impose on the participant, the high intensity and thus reduced time spent in physical exercise, the affiliation with CrossFit boxes, and the promotion of a sense of community, as well as the recording of personal records in the exercises and training that stimulate competitiveness. These factors were related to motivation and adherence in the selected studies, and applications from the results must be performed inside the boxes. However, we acknowledge that the listed factors are based on associations through observational studies, thus intervention studies are needed.

\section{Strengths and limitations}

We summarized the findings of all the empirical studies on the psychological variables of CrossFit participants to provide an overall examination of the body of knowledge related to the topic, including quality assessment and practical implications. This allows instructors, gym managers, participants, and researchers to consider practical applications and future research directions.

Although there are few studies published to date, growing interest in the psychological consequences of CrossFit participation reflects that in the broader HIFT literature [70]. The number of studies in the present review reveals that the psychological variables have been more investigated more than other topics on CrossFit. In a review analysing the literature on CrossFit, Claudino et al. [13] found 11 studies on psychosocial behaviour, 7 on the risk of musculoskeletal injury, 4 on body composition, and 4 on aspects of life and health. The comprehensive characteristic of this work allowed the inclusion of 34 studies, while Feito, Brown and Olmos [70] and Gianzina and Kassotaki [25] found only 13 and 3 studies on psychological parameters, respectively.

As limitation of this work, we did not perform a metaanalysis as part of our systematic review, because we felt such an analysis was not warranted given our motivations of the review, and given that our review is not focused on a specific outcome, as well as the heterogeneity (mainly methodological) of the data.

\section{Conclusion}

This review aimed to synthesise the literature on the psychological variables of CrossFit participants. The review of the studies showed that the adherence and maintenance of the practice of CrossFit are related to psychological aspects such as motivation and satisfaction of basic psychological needs; however, this is preliminary evidence. In the studies, CrossFit participants demonstrated high perception of effort, intrinsic motivation, and reasons for practice such as enjoyment, challenge, and affiliation. CrossFit has characteristics related to training and competition that seem to satisfy the basic psychological needs of the participantsrelatedness, autonomy, and competence, which compose the weekly practice frequency associated with basic psychological needs.

The low number of selected studies that were published before 2014 reveals that research on the psychological variables of CrossFit participants remains at an initial stage. Therefore, although we found relationships mainly between the CrossFit practice and the motivation and basic psychological needs of participants, the findings should be generalised with caution. It is essential for more studies to be published with high methodological quality to allow better analysis of the results and greater power of evidence for future conclusions.

The results have practical implications mainly regarding motivation and adherence of participants. Through the review, we identified the need for more and better quality studies, as well as intervention studies to investigate the effects of CrossFit practice on mental health, mood, stress, self-esteem, and anxiety among participants.

Author contributions All authors contributed to the study conception and design. Material preparation, data collection and analysis were performed by FHD, TTS, TCS and AA. The first draft of the manuscript 
was written by FHD and all authors commented on previous versions of the manuscript. All authors read and approved the final manuscript.

Funding This research was funding by the Coordenação de Aperfeiçoamento de Pessoal de Nível Superior-Brazil (CAPES)—Finance Code 001 and FAPESC-Foundation for research and innovation support of the State of Santa Catarina-Grant number 2019031000035 and call number 04.2018 .

\section{Compliance with ethical standards}

Conflict of interest The authors reported no potential conflict of interest.

Ethical approval Not applicable.

Informed consent Not applicable.

Systematic registration Registration in the International Prospective Register of Systematic Review (PROSPERO registry) was performed prior study initiation (registration number CRD42018091177).

\section{References}

1. American College of Sports Medicine (2015) Extreme Conditioning Programs. https://www.acsm.org/docs/default-source/broch ures/extreme-conditioning-programs.pdf

2. Knapik J (2015) Extreme conditioning programs: potential benefits and potential risks. J Spec Oper Med 15(3):108-113

3. Lichtenstein MB, Jensen TT (2016) Exercise addiction in CrossFit: prevalence and psychometric properties of the Exercise Addiction Inventory. Addict Behav Rep 3:33-37

4. Tibana RA, de Farias DL, Nascimento D, Da Silva-Grigoletto ME, Prestes J (2016) Relação da força muscular com o desempenho no levantamento olímpico em praticantes de CrossFit ${ }^{\circledR}$. Revista Andaluza de Medicina del Deporte 112:84-88

5. Moran S, Booker H, Staines J, Williams S (2017) Rates and risk factors of injury in CrossFit: a prospective cohort study. J Sports Med Phys Fitness 57(9):1147-1153

6. Glassman G (2017). CrossFit Affiliate Map. https://map.crossfit. $\mathrm{com} /$

7. Fisher J, Sales A, Carlson L, Steele J (2016) A comparison of the motivational factors between CrossFit participants and other resistance exercise modalities: a pilot study. J Sports Med Physical Fitness 9:1227-1234

8. Heinrich KM, Patel PM, O'Neal JL, Heinrich BS (2014) Highintensity compared to moderate-intensity training for exercise initiation, enjoyment, adherence, and intentions: an intervention study. BMC Public Health 14(1):789

9. Sibley BA, Bergman SM (2017) What keeps athletes in the gym? Goals, psychological needs, and motivation of CrossFit ${ }^{\mathrm{TM}}$ participants. Int J Sport Exerc Psychol 16(5):1-20

10. Spindler DJ, Allen MS, Vella SA, Swann C (2018) The psychology of elite cycling: a systematic review. J Sports Sci 36(17):1-12

11. McMahon EM, Corcoran P, O'Regan G, Keeley H, Cannon M, Carli V et al (2017) Physical activity in European adolescents and associations with anxiety, depression and well-being. Eur Child Adolesc Psychiatry 26(1):111-122

12. Andrade A, Bevilacqua GG, Coimbra DR, Pereira FS, Brandt R (2016) Sleep quality, mood and performance: a study of elite Brazilian volleyball athletes. J Sports Sci Med 15(4):601
13. Claudino JG, Gabbett TJ, Bourgeois F, de Sá SH, Miranda RC, Mezêncio B et al (2018) CrossFit overview: systematic review and meta-analysis. Sports Med Open 4(1):11

14. Bellar D, Hatchett A, Judge L, Breaux M, Marcus L (2015) The relationship of aerobic capacity, anaerobic peak power and experience to performance in CrossFit exercise. Biol Sport 32(4):315

15. Dominski FH, Siqueira TC, Serafim TT, Andrade A (2018) Injury profile in CrossFit practitioners: systematic review. Fisioterapia e Pesquisa 25(2):229-239

16. Dominski FH, Matias TS, Serafim TT, Feito Y (2020) Motivation to CrossFit training: a narrative review. Sport Sci Health 16(2):195-206

17. Dominski FH, Vilarino GT, Coimbra DR, Silva RB, Casagrande PdO, Andrade A (2018) Analysis of scientific production related to sports psychology in sports science journals of portuguese language. J Phys Educ 29(e2930):1-14

18. Pereira ES, Krause Neto W, Calefi AS, Georgetti M, Guerreiro L, Zocoler CAS, Gama EF (2019) Extreme conditioning training: acute effects on mood state. Revista Brasileira de Medicina do Esporte 25(2):137-141

19. Wilke J, Pfarr T, Möller MD (2020) Even warriors can be scared: a survey assessing anxiety and coping skills in competitive crossfit athletes. Int J Environ Res Public Health 17(6):1874

20. Freire GLM, da Silva Paulo JR, da Silva AA, Batista RPR, Alves JFN, do Nascimento Junior JRA (2020) Body dissatisfaction, addiction to exercise and risk behaviour for eating disorders among exercise practitioners. J Eat Disord 8(1):1-9

21. Teixeira PJ, Carraça EV, Markland D, Silva MN, Ryan RM (2012) Exercise, physical activity, and self-determination theory: a systematic review. Int J Behav Nutr Phys Act 9(1):78

22. Marcone M (2017) The impact of coaching styles on the motivation and performance of athletes. Kinesiology, Sport Studies, and Physical Education Synthesis Projects. 21

23. Whiteman-Sandland J, Hawkins J, Clayton D (2016) The role of social capital and community belongingness for exercise adherence: an exploratory study of the CrossFit gym model. J Health Psychol 23:1545-1556

24. Heinrich KM, Becker C, Carlisle T, Gilmore K, Hauser J, Frye J, Harms CA (2015) High-intensity functional training improves functional movement and body composition among cancer survivors: a pilot study. Eur J Cancer Care 24(6):812-817

25. Gianzina EA, Kassotaki OA (2019) The benefits and risks of the high-intensity CrossFit training. Sport Sci Health 15(1):21-33

26. Pickett AC, Goldsmith A, Damon Z, Walker M (2016) The influence of sense of community on the perceived value of physical activity: a cross-context analysis. Leisure Sci 38(3):199-214

27. Podmore M, Ogle J (2018) The lived experience of CrossFit as a context for the development of women's body image and appearance management practices. Fash Text 5(1):1-23

28. Mangine GT, Stratton MT, Almeda CG, Roberts MD, Esmat TA, VanDusseldorp TA, Feito Y (2020) Physiological differences between advanced CrossFit athletes, recreational CrossFit participants, and physically-active adults. PLoS ONE 15(4):e0223548

29. Moher D, Shamseer L, Clarke M, Ghersi D, Liberati A, Petticrew $M$ et al (2015) Preferred reporting items for systematic review and meta-analysis protocols (PRISMA-P) 2015 statement. Syst Rev $4(1): 1$

30. Horsley T, Dingwall O, Sampson M (2011) Checking reference lists to find additional studies for systematic reviews. Cochrane Database Syst Rev 10(8):MR000026

31. Schardt C, Adams MB, Owens T, Keitz S, Fontelo P (2007) Utilization of the PICO framework to improve searching PubMed for clinical questions. BMC Med Inform Decis Mak 7:16

32. Vandenbroucke JP, Von Elm E, Altman DG, Gøtzsche PC, Mulrow CD, Pocock SJ et al (2007) Strengthening the Reporting of 
Observational Studies in Epidemiology (STROBE): explanation and elaboration. PLoS Med 4(10):e297

33. O'Brien BC, Harris IB, Beckman TJ, Reed DA, Cook DA (2014) Standards for reporting qualitative research: a synthesis of recommendations. Acad Med 89(9):1245-1251

34. Smart NA, Waldron M, Ismail H, Giallauria F, Vigorito C, Cornelissen V et al (2015) Validation of a new tool for the assessment of study quality and reporting in exercise training studies: TESTEX. Int J Evid Based Healthc 13(1):9-18

35. Perciavalle V, Marchetta NS, Giustiniani S, Borbone C, Perciavalle V, Petralia MC et al (2016) Attentive processes, blood lactate and CrossFit@. Phys Sportsmed 44(4):403-406

36. Davies MJ, Coleman L, Stellino MB (2016) The relationship between basic psychological need satisfaction, behavioral regulation, and Participation in CrossFit. J Sport Behav 39(3):239

37. Bycura D, Feito Y, Prather C (2017) Motivational factors in CrossFit ${ }^{\circledR}$ training participation. Health Behav Policy Rev 4(6):539-550

38. Coyne P, Woodruff SJ (2020) Examining the influence of CrossFit participation on body image, self-esteem, and eating behaviours among women. J Phys Educ Sport 20(3):1314-1325

39. Martínez B-A, Gómez-Mármol A (2015) Percepción de esfuerzo, diversión y aprendizaje en alumnos de educación secundaria en las clases de Educación Física durante una Unidad Didáctica de CrossFit. SPORT TK-Revista EuroAmericana de Ciencias del Deporte 4(1):63-68

40. Heinrich KM, Crawford DA, Johns BR, Frye J, Gilmore KE (2020) Affective responses during high-intensity functional training compared to high-intensity interval training and moderate continuous training. Sport Exerc Perform Psychol 9(1):115

41. Partridge JA, Knapp BA, Massengale BD (2014) An investigation of motivational variables in CrossFit facilities. J Strength Cond Res 28(6):1714-1721

42. Swami V (2019) Is CrossFit Associated with More Positive Body Image? A Prospective Investigation in Novice CrossFitters. Int $\mathbf{J}$ Sport Psychol 50(4):370-381

43. Box AG, Feito Y, Brown C, Heinrich KM, Petruzzello SJ (2019) High Intensity Functional Training (HIFT) and competitions: how motives differ by length of participation. PLoS ONE 14(3):e0213812

44. Eather N, Morgan PJ, Lubans DR (2016) Effects of exercise on mental health outcomes in adolescents: findings from the CrossFit $^{\mathrm{TM}}$ teens randomized controlled trial. Psychol Sport Exerc 26:14-23

45. Drake N, Smeed J, Carper MJ, Crawford DA (2017) Effects of short-term CrossFit ${ }^{\mathrm{TM}}$ training: a magnitude-based approach. J Exerc Physiol Online 20(2):111-133

46. Simpson D, Prewitt-White TR, Feito Y, Giusti J, Shuda R (2017) Challenge, commitment, community, and empowerment: factors that promote the adoption of CrossFit as a training program. Sport J 1:1-14

47. Nielsen G, Wikman JM, Jensen CJ, Schmidt JF, Gliemann L, Andersen TR (2014) Health promotion: the impact of beliefs of health benefits, social relations and enjoyment on exercise continuation. Scand J Med Sci Sports 24(S1):66-75

48. Bailey B, Benson AJ, Bruner MW (2017) Investigating the organisational culture of CrossFit. Int J Sport Exerc Psychol 17(3):197-211

49. Köteles F, Kollsete M, Kollsete H (2016) Psychological concomitants of crossfit training: does more exercise really make your everyday psychological functioning better? Kinesiol Int J Fundam Appl Kinesiol 48(1):39-48

50. Feito Y, Brown C, Box A, Heinrich KM, Petruzzello SJ (2018) An investigation into how motivational factors differed among individuals engaging in CrossFit training. SAGE Open $8(3): 2158244018803139$
51. Ayar H (2018) Effects of motivation in participating to Crossfit centers with the purpose of recreative exercise. Eur J Phys Educ Sport Sci 4(1):72-79

52. Marin DP, Polito LFT, Foschini D, Urtado CB, Otton R (2018) Motives, motivation and exercise behavioral regulations in CrossFit and resistance training participants. Psychology 9(14):2869

53. Box AG, Feito Y, Brown C, Petruzzello SJ (2019) Individual differences influence exercise behavior: how personality, motivation, and behavioral regulation vary among exercise mode preferences. Heliyon 5(4):e01459

54. Box AG, Feito Y, Matson A, Heinrich KM, Petruzzello SJ (2019) Is age just a number? Differences in exercise participatory motives across adult cohorts and the relationships with exercise behaviour. Int J Sport Exerc Psychol 1-13. https://doi. org/10.1080/1612197X.2019.1611903

55. Woolf J, Lawrence H (2017) Social identity and athlete identity among CrossFit members: an exploratory study on the CrossFit Open. Manag Sport Leisure 22(3):166-180

56. Box A, Feito Y, Petruzzello S, Mangine G (2018) Mood state changes accompanying the Crossfit Open ${ }^{\mathrm{TM}}$ competition in healthy adults. Sports 6(3):67

57. Sławińska M, Stolarski M, Jankowski KS (2019) Effects of chronotype and time of day on mood responses to CrossFit training. Chronobiol Int 36(2):237-249

58. Kolomiitseva O, Prykhodko I, Prikhodko A, Anatskyi R, Turchynov A, Fushev S, Garkavyi O (2020) Efficiency of physical education of university students based on the motivation choice of the CrossFit program. Phys Act Rev 8:26-38

59. Liz CM, Viana MS, Dominski FH, Andrade A (2018) Physical exercises in gyms: Perspectives of the self-determination theory. Revista Iberoamericana de Psicología del Ejercicio y el Deporte 13(2):235-243

60. Ekkekakis P, Parfitt G, Petruzzello SJ (2011) The pleasure and displeasure people feel when they exercise at different intensities. Sports Med 41(8):641-671

61. Reljic D, Lampe D, Wolf F, Zopf Y, Herrmann HJ, Fischer J (2019) Prevalence and predictors of dropout from high-intensity interval training in sedentary individuals: a meta-analysis. Scand J Med Sci Sports 00:1-17

62. Ryan RM, Deci EL (2000) Self-determination theory and the facilitation of intrinsic motivation, social development, and well-being. Am Psychol 55(1):68

63. Deci EL, Ryan RM (2002) Handbook of self-determination research. University Rochester Press, Rochester

64. Rouse PC, Ntoumanis N, Duda JL, Jolly K, Williams GC (2011) In the beginning: role of autonomy support on the motivation, mental health and intentions of participants entering an exercise referral scheme. Psychol Health 26(6):729-749

65. Alix-Sy D, Le Scanff C, Filaire E (2008) Psychophysiological responses in the pre-competition period in elite soccer players. J Sports Sci Med 7(4):446

66. Lane A, Chappell R (2001) Mood and performance relationships among players at the world student games basketball competition. J Sport Behav 24(2):182-196

67. Vieira L, Oliveira J, Gaion P, Oliveira H, Rocha P, Vieira J (2010) Mood states and training: a study with high performance deep runners athletes. Revista da Educação Física/UEM 21(4):585-591

68. Matias TS, Dominski FH, Marks D (2020) Human needs in COVID-19 isolation. J Health Psychol. https://doi. org/10.1177/1359105320925149

69. Dominski FH, Brandt R (2020) Do the benefits of exercise in indoor and outdoor environments during the COVID-19 pandemic outweigh the risks of infection? Sport Sci Health 1-6. https://doi. org/10.1007/s11332-020-00673-z 
70. Feito Y, Brown C, Olmos A (2019) A content analysis of the High-Intensity Functional Training Literature: a look at the past and directions for the future. Human Movement 20(2):1-15

71. Glass SC, Knowlton RG, Becque MD (1994) Perception of effort during high-intensity exercise at low, moderate and high wet bulb globe temperatures. Eur J Appl Physiol 68(6):519-524

72. Hoare E, Stavreski B, Jennings GL, Kingwell BA (2017) Exploring motivation and barriers to physical activity among active and inactive Australian adults. Sports 5(3):47

73. Bergeron MF, Nindl BC, Deuster PA, Baumgartner N, Kane SF, Kraemer WJ, O'Connor FG (2011) Consortium for Health and Military Performance and American College of Sports Medicine consensus paper on extreme conditioning programs in military personnel. Curr Sports Med Rep 10(6):383-389

74. Tibana RA, de Sousa N, Cunha G, Prestes J, Fett C, Gabbett T, Voltarelli F (2018) Validity of session rating perceived exertion method for quantifying internal training load during high-intensity functional training. Sports 6(3):68

Publisher's Note Springer Nature remains neutral with regard to jurisdictional claims in published maps and institutional affiliations. 